\title{
Erupção dental em pacas (Agouti paca) criadas em cativeiro
}

\author{
[Dental eruption in pacas (Agouti paca) bred in captivity] \\ F.S. Oliveira ${ }^{1}$, J.C. Canola ${ }^{2 *}$ \\ ${ }^{1}$ Aluno de pós-graduação - FCAV-UNESP \\ ${ }^{2}$ Faculdade de Ciências Agrárias e Veterinárias - UNESP \\ Via de Acesso Paulo Donato Castellane, $\mathrm{s} / \mathrm{n}$ \\ 14883-800 - Jaboticabal, SP
}

\begin{abstract}
RESUMO
Fez-se o acompanhamento radiográfico mensal da erupção dental de cinco fêmeas e sete machos da espécie Agouti paca durante 30 meses. Os animais foram radiografados mês-a-mês. As pacas nasceram com três dentes em cada hemiarcada dental, um incisivo de crescimento contínuo por toda a vida, um prémolar decíduo (o único que é decíduo) e um molar. No quarto mês houve a erupção do segundo molar. O nivelamento da superfície de oclusão dos dentes inferiores ocorreu no sexto mês e o dos superiores ao redor do nono mês. No $14^{\circ}$ mês, houve o início da erupção do terceiro molar e, no $16^{\circ}$ mês, a evidenciação radiográfica do pré-molar permanente, ainda com preservação de correspondente decíduo. No $21^{\circ}$ mês, ocorreu o nivelamento da superfície de oclusão dos quatro dentes superiores e inferiores. Entre o $22^{\circ}$ e o $24^{\circ}$ mês, iniciou-se a queda dos pré-molares decíduos inferiores e, entre o $23^{\circ}$ e o $24^{\circ}$ mês, a dos superiores. Entre o $24^{\circ}$ e o $25^{\circ}$ mês, a superfície de oclusão dos dentes inferiores estava nivelada, e a dos dentes superiores aconteceu no $27^{\circ}$ mês.
\end{abstract}

Palavras-chave: paca, erupção dental, cativeiro

\begin{abstract}
Five females and seven males of Agouti paca were used to study dental eruption. In a monthly radiographic survey of the dental eruption, during 30 consecutive months, animals were radiographed. Pacas were born with three teeth in each dental hemiarcade, one incisor of continuous growth, one premolar (the only one deciduous) and one molar. The second molar erupted in the fourth month. The occlusal surfaces of lower teeth were at the same level in the sixth month and the upper teeth around ninth month. The beginning of the third molar eruption occurred in the 14th month. Perception of the first permanent premolar was around the 16th month, and its correspondent deciduous was still retained. The occlusal surfaces of upper and lower teeth were at the same level in the 21st month. The eruption of the first lower deciduous premolar occurred between the 22nd and 24th month and the upper's between the 23rd and 24th month. The occlusal surfaces of lower teeth were at the same level between the 24th and 25th month and the upper's on the 27th month.
\end{abstract}

Keywords: dental eruption, agouti paca, captivity

Recebido em 14 de outubro de 2004

Aceito em 18 de janeiro de 2007

*Autor para correspondência (corresponding author)

E-mail: canola@fcav.unesp.br 


\section{INTRODUÇ̃̃O}

Poucas são as informações existentes na literatura em relação à odontologia em espécies silvestres, principalmente quando se trata de erupção dental. Nos animais domésticos, a erupção dental é um processo bem descrito, principalmente porque eles apresentam duas dentições, uma decídua e outra permanente.

O conjunto temporário de dentes consiste de incisivos, caninos e pré-molares. Eles são substituídos por dentes permanentes das mesmas designações (Sisson, 1986; König et al., 2004), exceto o primeiro pré-molar do cão e do suíno, os quais não têm predecessores temporários (König et al., 2004). Os molares não são precedidos por dentes temporários e, assim, são parte do conjunto permanente (Sisson, 1986; König et al., 2004). Além disso, a troca dos dentes dos animais domésticos inicia-se com grande regularidade, de tal forma que pode ser correlacionada com a idade (König et al., 2004).

Em relação à paca, um dos maiores roedores brasileiros, Moojen (1952) relatou a presença de sulcos nos dentes molares, citando que o terceiro molar é o maior de todos. Eisenberg (1989) descreveu que nessa espécie há um par de dentes incisivos, nenhum dente canino, um par de dentes pré-molares e três pares de dentes molares, totalizando dez dentes em cada arcada no adulto.

A dieta de ratos, camundongos e hamsters, à base de sementes, grãos e tubérculos, alimentos altamente energéticos, exige pouca mastigação. Assim, essas espécies necessitam apenas de uma superfície de mastigação pequena nos dentes molares e não requerem substituição constante dos dentes. Esses animais apresentam três dentes molares braquiodontes (coroa curta) em cada quadrante da mandíbula, os quais têm raízes anatômicas e param de crescer quando a erupção se completa (Crossley, 1995).

Chinchilas e cobaios são herbívoros extrínsecos e requerem mastigação severa, que resulta em evidente desgaste dental do pré-molar e dos três molares em cada quadrante da mandíbula. Como os incisivos, estes dentes nunca formam raiz anatômica, crescendo continuamente para compensar o desgaste constante. Os pré-molares e os molares não estão dispostos em arranjos paralelos como no rato, divergindo de rostral a caudal (Crossley, 1995).

A forma de crescimento dos pré-molares e molares do camundongo campestre (Clethryoomys glareolus) é intermediária entre a dos dentes braquiodônticos de ratos $\mathrm{e}$ camundongos e a dos dentes arradiculares hipsodontes, de chinchilas e cobaias, sendo semelhantes à dos cavalos. Esses dentes apresentam crescimento contínuo até a reserva da coroa atingir a raiz (Crossley et al., 1999).

Em roedores, a fórmula dentária não excede 22 dentes permanentes, sendo um incisivo, nenhum canino, dois pré-molares maxilares (três na mandíbula) e três molares em cada hemiarcada dentária. Os incisivos escalprifomes crescem de polpas persistentes, e o esmalte dos dentes superiores não alcança a superfície interna (Gómez-Alvarez e Serrano, 1983). Hunt et al. (1970) descreveram que em ratos as superfícies mastigatórias dos molares apresentam dobras de esmalte orientadas transversalmente e tubérculos. Até nove tubérculos podem ser encontrados em um dente molar de animal jovem. Dependendo do desgaste, três dobras principais transversas (quatro no segundo molar) podem ser encontradas no adulto. $\mathrm{O}$ primeiro molar apresenta cinco raízes, o segundo quatro, e o terceiro três, na maxila; na mandíbula, quatro, três e três, respectivamente (Schneider, 1970 citado por Hebel e Stromberg, 1986).

O objetivo deste trabalho foi avaliar radiograficamente a erupção dental em pacas criadas em cativeiro e estudar sua relação com a idade do animal.

\section{MATERIAL E MÉTODOS}

Foram utilizadas 12 pacas, cinco fêmeas e sete machos, pertencentes ao setor de animais silvestres do Departamento de Zootecnia da Faculdade de Ciências Agrárias e Veterinárias de Jaboticabal - UNESP. A idade dos animais no início do experimento variou de zero a 15 meses e todos apresentaram identificação individual por microchips aplicados na região cervical dorsal, o que possibilitou o reconhecimento e a determinação precisa da idade de cada um deles. O acompanhamento radiográfico mensal começou em diferentes idades, dependendo do 
animal, e foi conduzido durante 30 meses consecutivos, de tal forma que em cada mês (de zero a 30) pelo menos quatro animais (dois de cada sexo) foram radiografados. Nem todos os animais foram radiografados todos os meses para se evitar o risco causado pela repetição da aplicação da anestesia, realizada com cetamina $(15 \mathrm{mg} / \mathrm{kg})$ e xilazina $(0,3 \mathrm{mg} / \mathrm{kg})$, via intramuscular na mesma seringa.

Na avaliação da erupção dental, os animais foram radiografados mensalmente, após a anestesia, em decúbito lateral, utilizando-se uma peça de madeira leve e radioluzente como abridor de boca, colocada entre os incisivos inferiores e superiores.

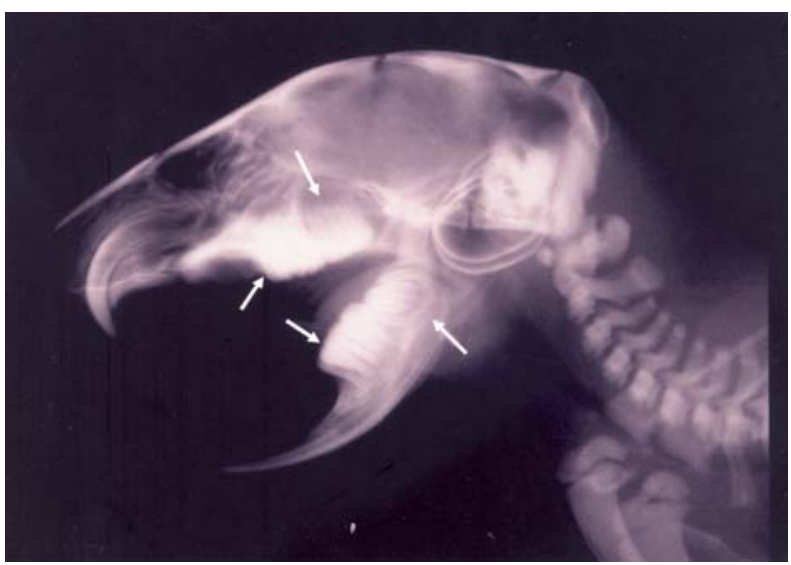

Figura 1. Imagem radiográfica da cabeça de neonato de paca macho, em decúbito lateral, ilustrando os dentes pré-molares e os molares (setas).

No terceiro mês de vida, houve a evidenciação radiográfica do segundo molar permanente e, no quarto mês, teve início sua erupção, o que levou cerca de um mês para se completar. O nivelamento das faces de oclusão dos dentes inferiores (pré-molar decíduo e primeiro e segundo molares) ocorreu no sexto mês e o dos superiores ao redor do nono mês de idade.

No $13^{\circ}$ mês, houve a evidenciação radiográfica do terceiro molar e, no $14^{\circ}$ mês, o início de sua erupção. No $16^{\circ}$ mês, ocorreu a evidenciação radiográfica do pré-molar permanente, ainda com preservação do correspondente decíduo, ou seja, o pré-molar apresenta-se na forma decídua e permanente, o que difere do primeiro pré-molar do cão e do suíno, que não possuem predecessores temporários, conforme relatado por König et al. (2004). Os molares não foram

\section{RESULTADOS E DISCUSSÃO}

A troca dos dentes na paca ocorreu com grande regularidade ao longo dos 30 meses, de tal forma que pôde ser estimada a idade, estando de acordo com a descrição de König et al. (2004) para mamíferos domésticos. Os animais nasceram com 12 dentes, ou seja, três em cada hemiarcada dental. O pré-molar é decíduo e os demais, incluindo os incisivos de crescimento contínuo por toda a vida e os molares, são permanentes (Fig. 1 e 2).

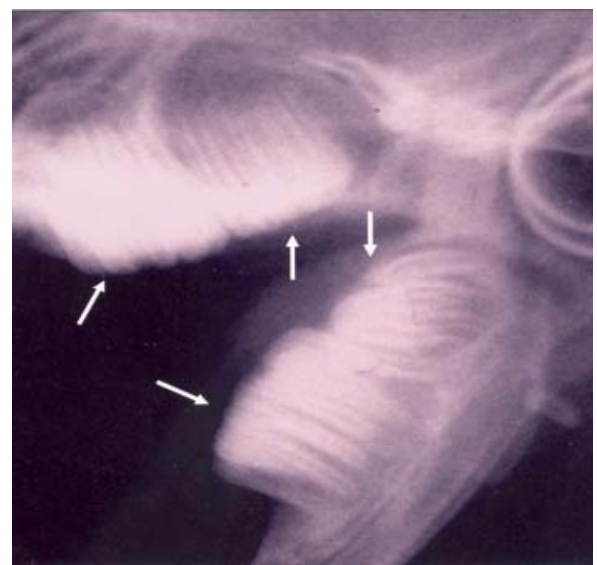

Figura 2. Imagem magnificada da figura anterior, ilustrando os dentes pré-molares e molares (setas).

precedidos por dentes temporários assim, são parte do conjunto permanente, o que está de acordo com a descrição de Sisson (1986) e König et al. (2004) para mamíferos domésticos.

No $21^{\circ}$ mês, ocorreu o nivelamento da face de oclusão dos quatro dentes superiores e inferiores.

Entre o $22^{\circ}$ e o $24^{\circ}$ mês, teve início a queda dos primeiros pré-molares decíduos inferiores e, entre o $23^{\circ}$ e o $24^{\circ}$ mês, a dos superiores (Fig. 3 e 4). Não houve evidenciação radiográfica de raízes nos dentes incisivos, pré-molares ou molares em pacas com até 24 meses, e entre 24 e 30 meses, a formação radicular no pré-molar inferior começou a ser discretamente evidenciada (Fig. 5). 
O nivelamento da face de oclusão dos dentes inferiores aconteceu entre o $24^{\circ}$ e o $25^{\circ}$ mês e o dos superiores, no $27^{\circ}$ mês. Assim, as pacas apresentam molares que não são substituídos, 0 que está de acordo com o descrito por Crossley (1995) para ratos, camundongos e hamsters. Diferentemente do descrito por esse autor para essas mesmas espécies de roedores, os dentes pré-molares e molares da paca não possuem raízes anatômicas evidentes radiograficamente até os 30 meses de idade, com exceção do pré- molar inferior, no qual discreta formação radicular começa a ser percebida.

Após os 27 meses de idade, as pacas apresentaram um dente incisivo, um pré-molar e três molares em cada hemiarcada, totalizando 20 dentes permanentes (Fig. 5), o que está de acordo com a descrição de Eisenberg (1989) para essa espécie.

A seqüência de eventos da erupção dental é apresentada na Tab. 1 .

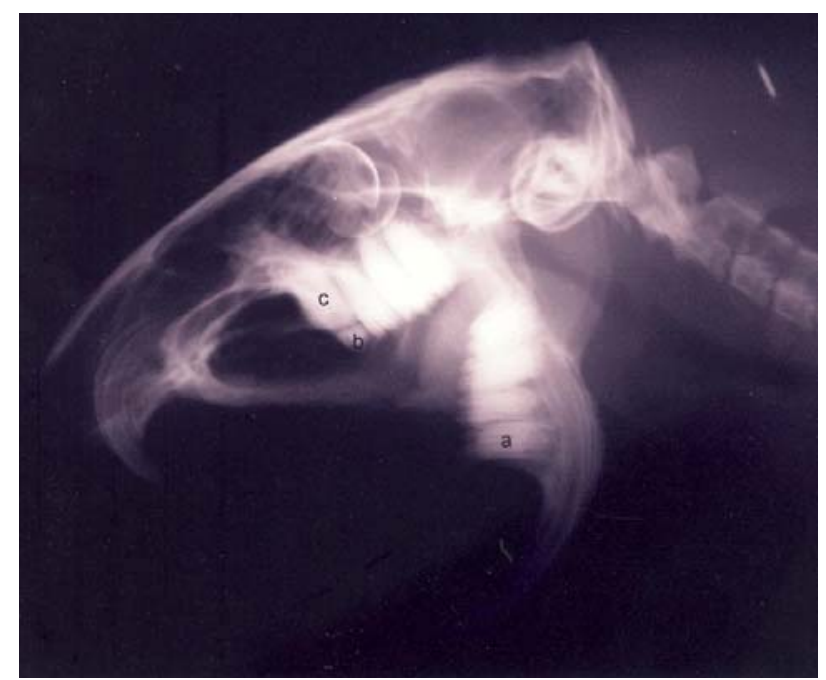

Figura 3. Imagem radiográfica da cabeça de paca fêmea de 22 meses de idade, em decúbito lateral, ilustrando a erupção do dente pré-molar inferior permanente (a) e a ausência do correspondente decíduo. Há, ainda, a preservação do dente pré-molar superior decíduo (b), embora esteja ocorrendo a erupção do correspondente permanente (c).

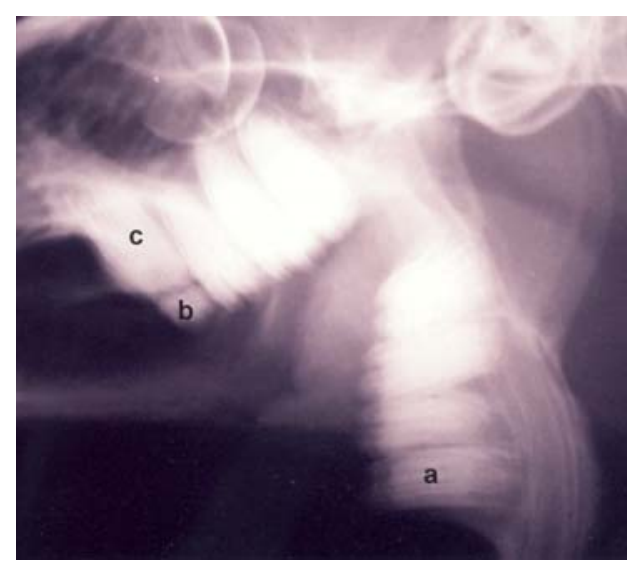

Figura 4. Imagem magnificada da figura anterior, ilustrando a erupção do pré-molar inferior permanente (a) e a ausência do correspondente decíduo. Há, ainda, a preservação do primeiro dente pré-molar superior decíduo (b), embora esteja ocorrendo a erupção do correspondente permanente (c).

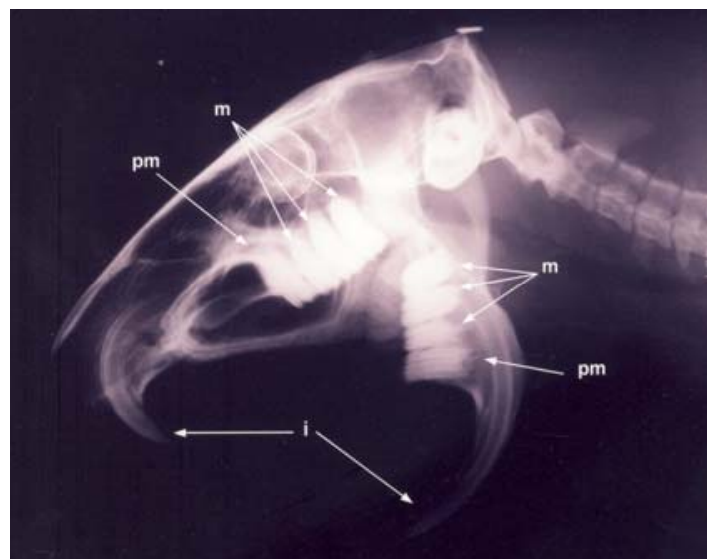

Figura 5. Imagem radiográfica da cabeça de paca fêmea de 30 meses de idade, em decúbito lateral, ilustrando os dentes incisivos (i), pré-molares (pm) e molares $(\mathrm{m})$. Note o início de formação radicular no pré-molar inferior. 
Tabela 1. Seqüência de eventos da erupção dental, ocorridos durante os 30 primeiros meses de vida de pacas criadas em cativeiro

\begin{tabular}{ll}
\hline $\boldsymbol{I D A D E}$ & $\boldsymbol{E} \boldsymbol{E} \boldsymbol{E N T O}$ \\
\hline 3 meses & Evidenciação radiográfica do segundo molar \\
4 meses & Erupção do segundo molar \\
6 meses & Nivelamento dos dentes inferiores \\
9 meses & Nivelamento dos dentes superiores \\
13 meses & Evidenciação radiográfica do terceiro molar \\
14 meses & Erupção do terceiro molar \\
16 meses & Evidenciação radiográfica do pré-molar permanente \\
$22-24$ meses & Erupção do pré-molar permanente inferior \\
$23-24$ meses & Erupção do pré-molar permanente superior \\
$24-25$ meses & Nivelamento da face de oclusão dos dentes inferiores \\
$25-30$ meses & Formação radicular no pré-molar inferior e início de sua evidenciação \\
$27-30$ meses & Nivelamento da face de oclusão dos dentes superiores \\
\hline
\end{tabular}

\section{REFERÊNCIAS BIBLIOGRÁFICAS}

CROSSLEY, D.A. Clinical Aspects of Rodent Dental Anatomy. J. Vet. Dent., v.12, p.131-135, 1995.

CROSSLEY, D.A.; SAN ROMÁN, F.; SÁNCHEZ, M. Odontologia em outras espécies de pequenos animais. In: SAN ROMÁN, F. Atlas de odontologia dos pequenos animais. São Paulo: Manole, 1999. p.243-257.

EISENBERG, J.F. Order rodentia. A preliminary analysis of neotropical mammal fauna: Mammals of the neotropics: the northern neotropics. Chicago: University of Chicago, 1989. v.1, p.395-397.

GÓMEZ-ÁLVAREZ, R.P.; SERRANO, M.N.M. Introducción a la histología animal comparada: atlas-libro de la estructura microscópica de los animals. Barcelona: Labor Universitaria, 1983. p.212-213.
HEBEL, R.; STROMBERG, M.W. Anatomy and embryology of the laboratory rat. Wörthsee: BioMed Verlag, 1986. p.9-21

HUNT, H.R.; ROSEN, S.; HOPPERT, C.A. Morphology of molar teeth and occlusion in young rats. J. Dental Res., v.49, p.508-514, 1970.

KÖNIG, H.E.; SAUTET, J.; LIEBICH, H.G. Aparelho digestório. In: KÖNIG, H.E.; LIEBICH, H-G. (Eds.). Anatomia dos animais domésticos: texto e atlas colorido. Porto Alegre: Artmed, 2004. v.2, p.15-33.

MOOJEN, J. Os roedores do Brasil. Rio de Janeiro: Biblioteca Científica Brasileira, 1952. p. $2-119$

SCHNEIDER, H.-G. Paradontologische studie über geschlechts- und zuchtstamm-bedingte merkmale in der molarenregion der albinoratte. Z. Versuchstierkd, v.12, p.137-154, 1970.

SISSON, S. In: SISSON, S.; GROSSMAN, J.D. Anatomia dos animais domésticos. 5.ed. Rio de Janeiro: Guanabara Koogan, 1986. v.1, p.100105. 